\title{
Daily variation patterns in seagrass photosynthesis along a vertical gradient
}

\author{
João Silva*, Rui Santos \\ Centro de Ciências do Mar (CCMAR), Universidade do Algarve, Campus de Gambelas, 8000-117 Faro, Portugal
}

\begin{abstract}
The relationship between the available photosynthetic active radiation (PAR) and the photosynthetic yield of Photosystem II (PSII), measured by chlorophyll a fluorescence, was assessed in the intertidal seagrasses of Ria Formosa, a coastal lagoon in southern Portugal. Most of the lagoon's intertidal is occupied by a monospecific population of Zostera noltii (Hornemann), which occupies a vertical gradient of about $2 \mathrm{~m}$. The upper distribution limit of this species comprises the edge of a Spartina maritima (Curtis) Fernald saltmarsh and the lower limit the transition to the subtidal, dominated by Cymodocea nodosa (Ucria) Ascherson. Diurnal changes in the pattern of rapid-light curves (RLCs) was investigated with pulse amplitude-modulated (PAM) fluorometry in $Z$. noltii and in $C$. nodosa in the upper and lower intertidal. The light reactions of photosynthesis were assessed by fitting photosynthesis-irradiance $(P-I)$ models to the RLCs. The photosynthetic parameters of $Z$. noltii revealed that this plant species exhibits sun- and shade-type responses in its upper and lower vertical distribution limits, respectively. At the lower distribution limit in low light, the initial slopes of all RLCs were significantly higher than at the upper site, but decreased with increasing irradiances, while at the upper distribution limit, although lower, the slopes were unaffected by increasing irradiance. C. nodosa presented a typical shade-type response, as evidenced by the daily variation and light dependence of both photosynthetic efficiency and optimal quantum yield. The relationship between the maximum electron-transport rate and irradiance suggests that this species is strongly light-limited. We suggest that attempts to characterize the photosynthetic behaviour of an intertidal meadow should consider both diurnal fluctuations in the plants' photosynthetic activity as well as its vertical distribution frequency.
\end{abstract}

KEY WORDS: Daily variation $\cdot$ Seagrasses $\cdot$ Intertidal $\cdot$ Photosynthesis $\cdot$ Pulse amplitude-modulated fluorescence $\cdot$ PAM $\cdot$ Zostera noltii $\cdot$ Cymodocea nodosa

Resale or republication not permitted without written consent of the publisher

\section{INTRODUCTION}

Intertidal seagrasses colonise one of the harshest marine habitats, in which conditions change very rapidly and in a very significant manner. Stress factors are imposed and relaxed in accordance with the combined rhythms of tides and diurnal irradiance. Plants are forced to maintain a permanent and very dynamic trade-off between photosynthetic efficiency and photoprotection.

Like their terrestrial relatives, seagrasses perform real-time adjustments in their photosynthetic activity in response to diurnal changes in the available photosynthetic active radiation (PAR) (Ralph et al. 1998).
Although photosynthesis usually parallels daily irradiance, a midday depression in photosynthetic activity may occur under high irradiance. This depression is common among marine plants, together with a realtime photoacclimation capacity expressed by rapid adjustments in pigment contents and ratios (Dennison \& Alberte 1986, Abal et al. 1994).

Light availability is considered to be the most important factor regulating the depth distribution of seagrass beds, and has been widely used in predicting the lower vertical limits of a number of species (Duarte 1991, Dennison et al. 1993, Kenworthy \& Fonseca 1996, Bach et al. 1998). The interaction between high nutrient loads, the concentration of phytoplankton and turbid- 
ity determines the light attenuation in the water column (Abal \& Dennison 1996, Koch 2001). These parameters may undergo considerable variations, either on long-term (e.g. seasonal) or short-term (e.g. daily, tidal) scales, particularly in meadows with an important intertidal component, where physical, chemical and biological parameters tend to vary more dramatically than in the subtidal environment.

Intertidal meadows are regularly exposed to oversaturating irradiances that induce light stress and aggravate conditions of thermal and desiccation stress. However, through morphological traits, intertidal plants usually cope well with desiccation (Leuschner et al. 1998, Björk et al. 1999). In this specific type of environment, the ability to cope with irradiances that can exceed saturation values by as much as 7 to 8 times appears to be the major prerequisite for plant survival.

Plants have the capacity to adapt to their light environment in a number of ways, from the morphological down to the biochemical level (Falkowski \& LaRoche 1991, Evans \& Poorter 2001). Physiologically, plants are able to regulate photosynthesis in a highly dynamic way in response to several external factors. When the factor is high irradiance, the response is usually photoprotection, involving non-photosynthetic thermal dissipation of energy through a process often called 'non-photochemical quenching' (Krause \& Weis 1991, Demmig-Adams 1998, Ort 2001). This response enables maintenance of the crucial balance between energy absorption and photosynthetic light utilization by carbon fixation, thus preventing photo-oxidative damages in Photosystem II (PS II; Ensminger et al. 2001).

Chlorophyll fluorescence measurements have proved to be very useful in the assessment of photosynthetic light responses, as the amount of energy dissipated in this way is inversely correlated to photosynthetic efficiency (Krause \& Weis 1991). The description of a linear relationship between the chlorophyll a fluorescence parameter $\left(F_{\mathrm{m}}{ }^{\prime}-F_{\mathrm{s}}\right) / F_{\mathrm{m}}{ }^{\prime}$ (where $F_{\mathrm{s}}$ is fluorescence in the light when only part of the reaction centres are closed, and $F_{\mathrm{m}}{ }^{\prime}$ is maximal fluorescence of a light-adapted leaf immediately after closure of all reaction centres by a saturating pulse) and the quantum yield of photosynthesis by Genty et al. (1989) opened the way for photosynthetic measurements using fluorometry-based instruments (Seaton \& Walker 1990). Subsequently, the pulse amplitude-modulated (PAM) fluorescence method has been widely used and improved (Schreiber et al. 1995). In situ measurements of chlorophyll fluorescence in seagrasses were made possible after the development of a submersible PAM fluorometer (Beer et al. 1998, Ralph et al. 1998, Björk et al. 1999, Beer \& Björk 2000, Schwarz et al. 2000, Seddon \& Cheshire 2001, Durako \& Kunzelman 2002). PAM fluorescence has been used for the evaluation of seagrass responses to specific environmental stresses such as desiccation, elevated temperatures or high irradiances. In parallel, it has also provided valuable insights into the dynamic behaviour of the photosynthetic apparatus of seagrass species under fluctuating field conditions. Chlorophyll fluorescence has proved to be particularly useful in the assessment of several aspects of the diurnal pattern of photosynthetic activity in seagrasses (Ralph et al. 1998, Enríquez et al. 2002, Figueroa et al. 2002), as it allows a considerable number of measures throughout the day under field conditions.

The existence of considerable alterations in photosynthetic performance during a diurnal cycle is widely recognised and must be taken into account when longterm measures or estimates of photosynthesis are required. On the other hand, in SW Europe, where tides are semi-diurnal, with daily changes in amplitude and time, the daily light regime in intertidal seagrass meadows fluctuates as a function of both time of day and tide schedule. When a third factor, the vertical distribution of plants within a meadow, is introduced, it becomes impossible to predict global photosynthetic performance without taking into consideration that a number of distinct light regimes occur simultaneously at different levels of a same meadow.

The aim of the present work was to assess how the vertical position of seagrasses in the intertidal determines their diurnal photosynthetic performance. The relationship between diurnal changes in available PAR and the photosynthetic yield of PSII, measured by chlorophyll a fluorescence, was investigated in the intertidal zone of Ria Formosa, southern Portugal, which is dominated by monospecific meadows of the seagrass Zostera noltii. The transition to the subtidal is colonised by a band of the seagrass Cymodocea nodosa.

\section{MATERIALS AND METHODS}

Study site and plant distribution. Ria Formosa is a shallow mesotidal lagoon on the south coast of Portugal. Its tidal amplitude varies between $3.50 \mathrm{~m}$ on spring tides and $1.30 \mathrm{~m}$ on neap tides. Zostera noltii (Hornemann) meadows occupy a vertical gradient of ca. $2 \mathrm{~m}$. Their upper distribution limit comprises the edge of the Spartina maritima (Curtis) Fernald saltmarsh and their lower distribution limit the transition to the subtidal, which is dominated by Cymodocea nodosa (Ucria) Ascherson. This transition zone emerges only at the lowest water level of spring tides, while the upper limit of the $Z$. noltii meadows has an average emersion period of 6 to $8 \mathrm{~h}$ per tidal cycle (12 h). Environmental conditions, particularly light, vary greatly throughout the intertidal seagrass habitat. In the win- 
ter, the lower edge of the meadows receives an average daily PAR dose of $4 \mathrm{~mol}$ photons $\mathrm{m}^{-2}$, whereas the upper edge receives around $15 \mathrm{~mol}$ photons $\mathrm{m}^{-2}$. The range of $\mathrm{pH}$ variations is also higher at the upper site ( $7.4 \mathrm{pH}$ at low tide, up to $8.8 \mathrm{pH}$ at high tide) than at the lower site ( 7.9 to $8.3 \mathrm{pH})$.

In southern Portugal $\left(37^{\circ} \mathrm{N}, 8^{\circ} \mathrm{W}\right)$, where tides are semidiurnal (2 low and 2 high tides every $24 \mathrm{~h}$ ), low tide occurs in the early morning and late afternoon during spring tides and at midday during neap tides (Fig. 1). The combination of this tidal rhythm with daily changes in solar radiation leads to strong differences in the light environment at the upper and lower edges of the seagrass meadows.

This experiment was conducted under the neap-tide conditions shown in Fig. 1b. Low tide was coincident with solar noon, allowing lower plants to receive the maximum possible PAR.

Sampling strategy. Rapid-light curves (RLCs) were obtained by PAM fluorometry (Diving-PAM, Walz) every 2 to $3 \mathrm{~h}$ from pre-dawn until sunset, for Cymodocea nodosa (transition to subtidal) and for 2 Zostera noltii sites ( 1 at its lowest and 1 at its highest intertidal edge). All measurements were performed in situ at ambient temperature $\left(16\right.$ to $\left.18^{\circ} \mathrm{C}\right)$. RLCs were obtained from 5 replicates for each site.

An underwater planar PAR measuring device (Li192SA underwater quantum sensor connected to a
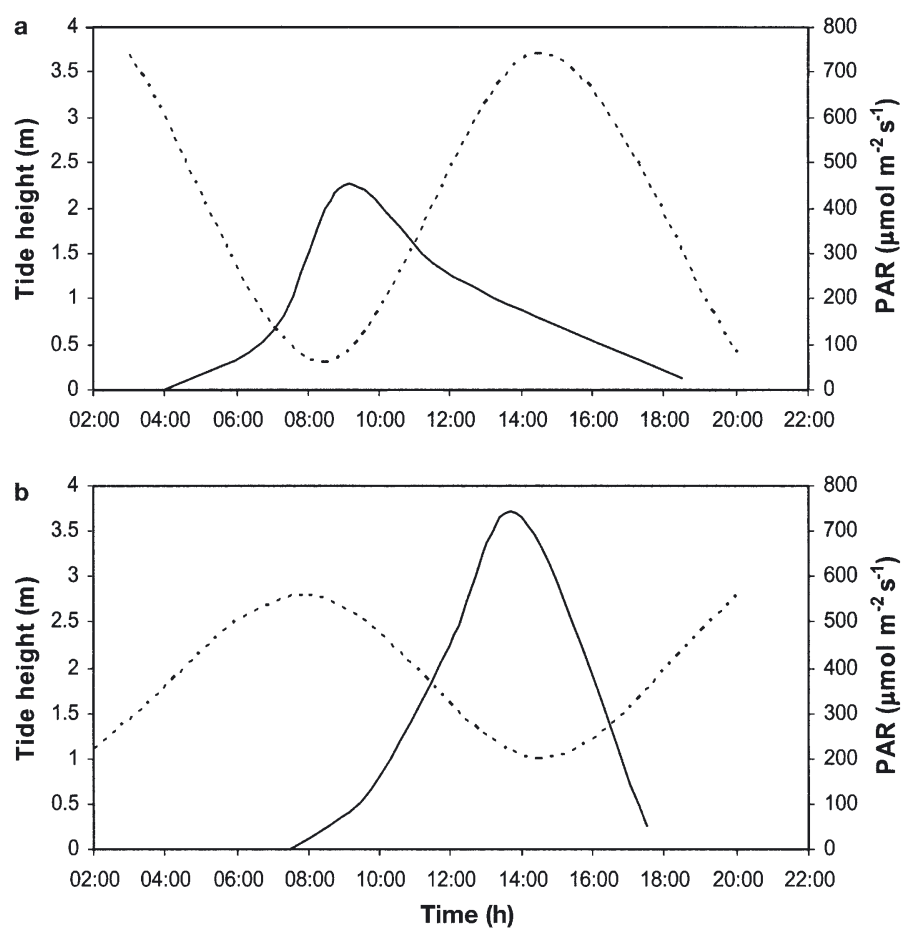

Fig. 1. Zostera noltii. Typical patterns of tidal cycle $(\cdots \cdots)$ and available photosynthetically active radiation, PAR (-), at lower end of a meadow during (a) spring and (b) neap tides
Li-1000 data logger; Li-Cor) mounted on a telescopic tower was installed in the transition between Zostera noltii and Cymodocea nodosa, at the exact location where samples of both species were collected. PAR radiation at the upper site of $Z$. noltii was measured with an identical set of instruments. Both devices were calibrated against each other.

Absorption factor (AF). The absorption factor (AF), which represents the fraction of incident PAR that is absorbed by the leaves, was determined according to Beer et al. (2000) by placing seagrass leaves on top of the fluorometer PAR quantum sensor and irradiating them perpendicularly at a fixed distance with the instrument's own optic fibre. Irradiance reaching the sensor with and without leaves was recorded underwater in 10 replicates of each species, and AF was calculated as the percentage of light absorbed by the leaves. The use of this specific absorption factor instead of the instrument's pre-defined and commonly used value of 0.84 allowed the calculation of absolute $\left(\mu \mathrm{mol} \mathrm{e}^{-} \mathrm{m}^{-2} \mathrm{~s}^{-1}\right)$ instead of relative electron-transport rates.

Fluorescence measurements. Seagrass leaves (2nd to 3 rd youngest for Zostera noltii and 3rd youngest for $\mathrm{Cy}$ modocea nodosa) were placed in the fluorometer leafdistance clip and shaded from ambient light for the duration of the measurement of each curve to prevent superimposition of ambient light on the light supplied by the instrument's optic fibre. Samples were irradiated with a series of 8 increasing pre-set irradiance steps supplied by the fluorometer's halogen lamp. At the end of each irradiance step ( $15 \mathrm{~s}$ periods), a $0.6 \mathrm{~s}$ saturatinglight pulse (ca. $4000 \mu \mathrm{mol}$ photons $\mathrm{m}^{-2} \mathrm{~s}^{-1}$ ) was applied for maximum fluorescence $\left(F_{\mathrm{m}}{ }^{\prime}\right)$ determination. Effective quantum yield of PS II $\left[Y=\left(F_{\mathrm{m}}{ }^{\prime}-F_{\mathrm{s}}\right) / F_{\mathrm{m}}{ }^{\prime}=\Delta F / F_{\mathrm{m}}{ }^{\prime}\right]$ (Genty et al. 1989) was computed and the electron-transport rate $[\mathrm{ETR}=Y \times$ irradiance $(I) \times \mathrm{AF} \times 0.5]$ (Schreiber et al. 1995) was calculated for each irradiance step.

The light reactions of photosynthesis were assessed by the parameters obtained directly through PAM fluorometry and by the parameters derived from the equation model fitted to the RLCs. The curves (ETR-I) were fitted with the adapted hyperbolic tangent model equation of Jassby \& Platt (1976): ETR $=$ ETR $_{m} \times$ $\tanh \left(\alpha \times I / \mathrm{ETR}_{\mathrm{m}}\right)$, where $I$ is irradiance, $\alpha$ is the ascending slope at limiting irradiances, and $\mathrm{ETR}_{\mathrm{m}}$ is the maximum electron-transport rate. The halfsaturation irradiance, $I_{k}$, was calculated as the ratio between $\mathrm{ETR}_{\mathrm{m}}$ and $\alpha$.

Parallel to the rapid-light curves, potential quantum yield $\left(F_{\mathrm{m}}-F_{\mathrm{o}} / F_{\mathrm{m}}=F_{\mathrm{v}} / F_{\mathrm{m}}\right)$ (where $F_{\mathrm{o}}$ is fluorescence in the dark when all reaction centres are open) was also assessed for both Zostera noltii types and for Cymodocea nodosa throughout the day. For this purpose, dark leaf-clips were used to dark-adapt portions of attached functional leaves. Leaves were left for $15 \mathrm{~min}$ 
(previously determined as being sufficient time for full oxidation of reaction centres) in the dark, after which a saturating-light pulse, identical to that used in the RLCs, was applied for determination of the potential quantum yield, expressed as $F_{\mathrm{v}} / F_{\mathrm{m}}$.

All results are presented as means $\pm \mathrm{SE}$. We used 1- or 2-way ANOVAs to test for the significant differences among variables $(\alpha=0.05)$ (Sokal \& Rohlf 1981). Tukey's HSD test was used to establish significant differences between individual means.

\section{RESULTS}

The absorption factor (AF) determined for Zostera noltii $(0.79 \pm 0.02)$ was lower than the standard value pre-introduced in the PAM $(0.84)$, whereas the AF of Cymodocea nodosa $(0.88 \pm 0.01)$ was higher. These values differed from each other and from the standard value and were therefore used to calculate the absolute electron-transport rates of the respective species. AF values for $Z$. noltii were identical along its vertical distribution in the intertidal.

The ambient photosynthetic active radiation reaching the 2 sampling sites followed a similar trend throughout the day, but with very different absolute values (Fig. 2). At the lower site, where both Zostera noltii and Cymodocea nodosa were sampled (Fig. 2b,c) PAR peaked at ca. $800 \mu \mathrm{mol} \mathrm{m} \mathrm{m}^{-2} \mathrm{~s}^{-1}$, while at the upper site (Fig. 2a) it reached $1400 \mu \mathrm{mol} \mathrm{m}^{-2} \mathrm{~s}^{-1}$. Considering the fact that low tide was around solar noon, the PAR measured at the lower site reached its highest possible value, which was almost half the irradiance measured at the upper site.

During the day, Cymodocea nodosa attained its highest maximum electron-transport rate, $\mathrm{ETR}_{\mathrm{m}}(69.9$ $\left.\pm 9.2 \mu \mathrm{mol} \mathrm{e} \mathrm{e}^{-} \mathrm{m}^{-2} \mathrm{~s}^{-1}\right)$, at solar noon (14:00 h) (Fig. 2c). At the same time, the upper-site Zostera noltii attained a similar value $\left(68.9 \pm 11.3 \mu \mathrm{mol} \mathrm{e} \mathrm{e}^{-} \mathrm{m}^{-2} \mathrm{~s}^{-1}\right.$; Fig. 2a). The ETR $_{\mathrm{m}}$ of $Z$. noltii at the lower site was significantly lower $\left(55.4 \pm 11.6 \mu \mathrm{mol} \mathrm{e} \mathrm{e}^{-} \mathrm{m}^{-2} \mathrm{~s}^{-1}\right.$, Fig. $\left.2 \mathrm{~b}\right)$, and was attained earlier, at 10:30 h. No significant changes in $\mathrm{ETR}_{\mathrm{m}}$ were observed until solar noon.

The half-saturation irradiances $\left(I_{k}\right)$ were always significantly higher for the upper site Zostera noltii than for plants from the lower site, more particularly from $12: 00$ to $16: 00 \mathrm{~h}$, the period of higher irradiance (Fig. 2). The $I_{k}$ of Cymodocea nodosa remained below those of the $2 Z$. noltii sites, except at 13:00 h, when it was significantly higher $\left(278 \mu \mathrm{mol} \mathrm{m} \mathrm{m}^{-2} \mathrm{~s}^{-1}\right)$. From solar noon to the end of the day, $I_{k}$ values for all plants decreased in parallel.

The initial slopes of Zostera noltii RLCs ( $\alpha$, Fig. 3) were always significantly higher at the lower site than at the upper site. In $Z$. noltii plants from both sites, $\alpha$ remained fairly constant throughout the day (Fig. 3a,b), in
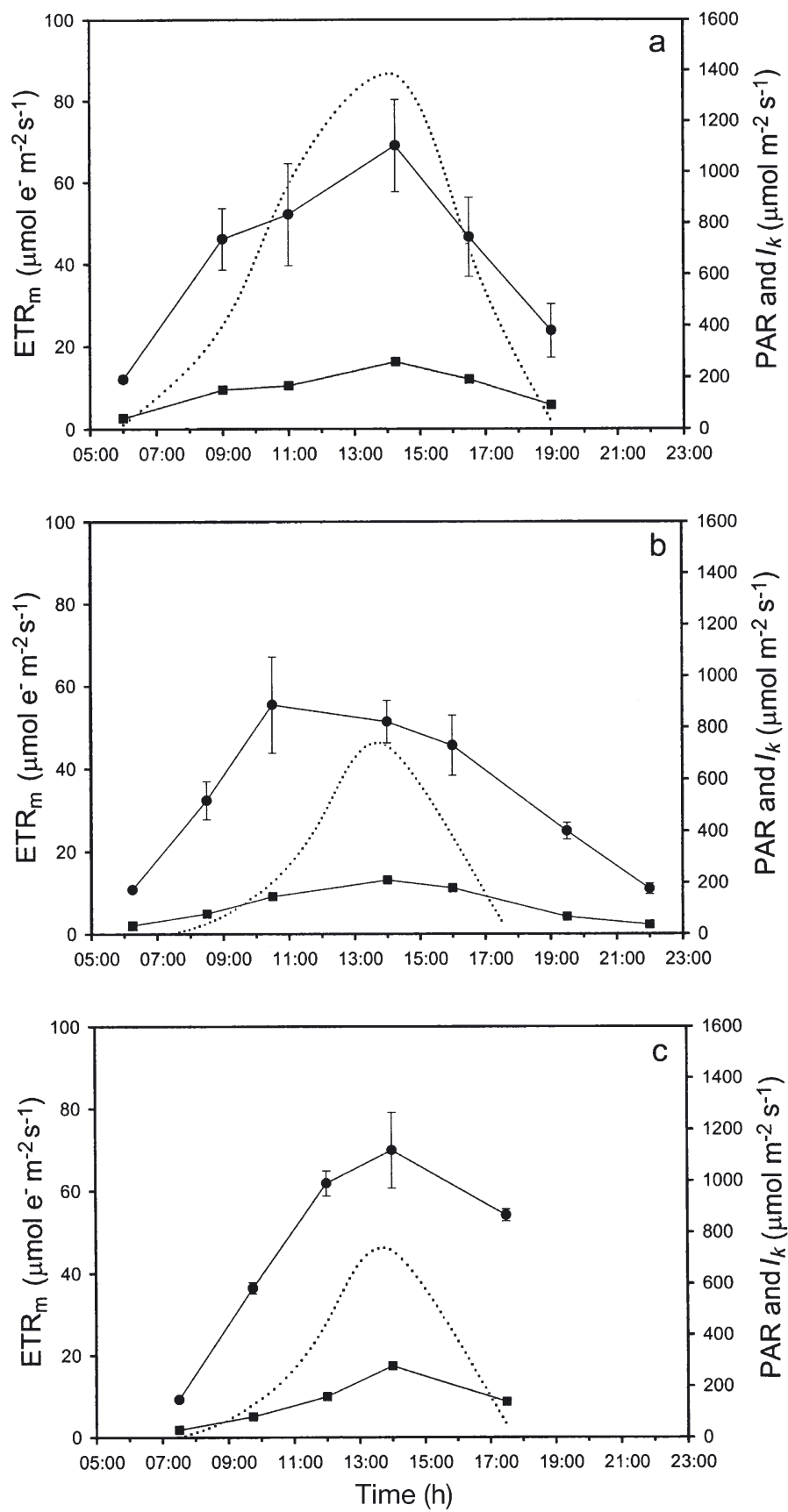

Fig. 2. Zostera noltii and Cymodocea nodosa. (a,b) Upper and lower Z. noltii sites, respectively; (c) C. nodosa site. Diurnal variation in $(\bullet)$ maximum electron-transport rate $\left(\mathrm{ETR}_{\mathrm{m}}\right)$,

$(\varpi)$ half-saturation irradiance $\left(I_{k}\right)$ and $(\cdots \cdots)$ PAR

contrast to Cymodocea nodosa, the $\alpha$ of which showed a very strong oscillatory tendency: it peaked in the early morning, with significantly higher values than $Z$. noltii, and decreased markedly at solar noon (Fig. 3c).

There were no significant changes in lower Zostera noltii $F_{\mathrm{v}} / F_{\mathrm{m}}$ throughout the day (Fig. $3 \mathrm{~b}$ ). At the upper site, 2 depressions were observed, 1 in the early morn- 

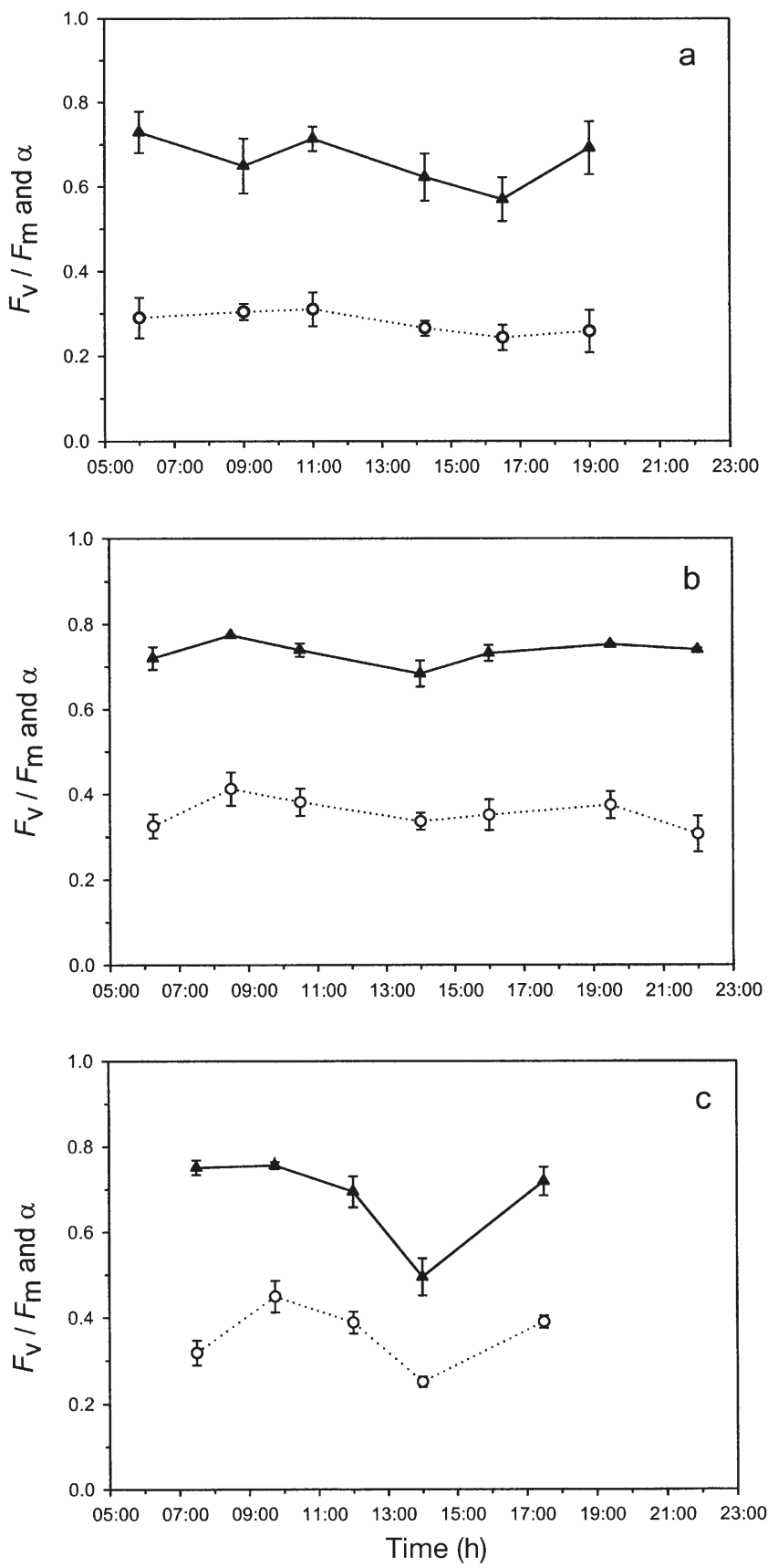

Fig. 3. Zostera noltii and Cymodocea nodosa. (a,b) Upper and lower Z. noltii sites, respectively; (c) C. nodosa site. Diurnal variation in ( $\mathbf{\Delta})$ optimum quantum yield $\left(F_{\mathrm{v}} / F_{\mathrm{m}}\right)$ and $(\mathrm{o})$ initial slope of rapid light curves $(\alpha)$

ing and 1 in the early afternoon (Fig. 3a). In Cymodocea nodosa, $F_{\mathrm{v}} / F_{\mathrm{m}}$ followed the same pattern as $\alpha$, with a marked midday depression and full recovery towards the afternoon (Fig. 3c).

For identical PAR values, the electron-transport rates of Cymodocea nodosa were always significantly higher than those of both Zostera noltii samples (Fig. 4). Nei- ther Z. noltii from the upper site nor C. nodosa showed any saturation tendency of $\mathrm{ETR}_{\mathrm{mi}}$ on the contrary, there was a clear tendency of increasing $\mathrm{ETR}_{\mathrm{m}}$ with increasing irradiance. The $\mathrm{ETR}_{\mathrm{m}}$ of the lower $Z$. noltii appears to have saturated at a medium irradiance of about $500 \mu \mathrm{mol} \mathrm{m}{ }^{-2} \mathrm{~s}^{-1}$, decreasing thereafter (Fig. 4b).

The upper Zostera noltii plants were less efficient at low light than both the lower $Z$. noltii and Cymodocea nodosa, but $\alpha$ remained constant with increasing PAR (Fig. 4). Both the lower Z. noltii and C. nodosa were significantly more efficient in the use of low light. For these plants, the initial slope of the RLCs, $\alpha$, peaked before $200 \mu \mathrm{mol} \mathrm{m} \mathrm{m}^{-2} \mathrm{~s}^{-1}$, and decreased with increasing irradiance thereafter. At higher irradiances $(750 \mu \mathrm{mol}$ $\mathrm{m}^{-2} \mathrm{~s}^{-1}$ ), the photosynthetic efficiency of the upper $Z$. noltii was about the same as that of both the lower Z. noltii and of C. nodosa.

\section{DISCUSSION}

The amount of light that can be absorbed by a leaf depends mostly on its pigment content (Beer et al. 2000). This implies that all environmental factors capable of influencing the pigment content of a plant are also responsible for changes in the absorption factor values. Such factors include geographical location, time of year, depth, leaf age and nutrient status. AF values in seagrasses are therefore expected to vary considerably, either interspecifically or even intraspecifically. One example of such variation is the difference between the AF value determined by Beer et al. (1998) for Cymodocea nodosa collected in the eastern Mediterranean (Israel) $(0.72 \pm 0.11)$ and the AF value measured in the present study $(0.88 \pm 0.01)$ for plants of the same species collected in south Portugal, which was higher than any published value for a seagrass species. In Ria Formosa, C. nodosa leaves are large, extremely thick, and highly pigmented (data not shown); this could explain its high optical density. The absorption factor determined for Zostera noltii (0.79 \pm 0.02), although lower than the standard value, was identical to the highest published values for seagrasses, namely Thalassia testudinum (Durako \& Kunzelman 2002).

Previously published AF values for seagrasses appear to have 2 common features: the considerable differences between them (from 0.44 in Zostera marina to 0.78 in Thalassia testudinum; Beer et al. 1998, Durako \& Kunzelman 2002) and the fact that all of them are lower than the standard value of 0.84 originally reported for terrestrial plants. Determination of the leaf AF is thus essential for calculating absolute electron-transport rates, particularly when relating ETR to oxygen production. Although the latter aspect was not examined in the present work, we still believe 

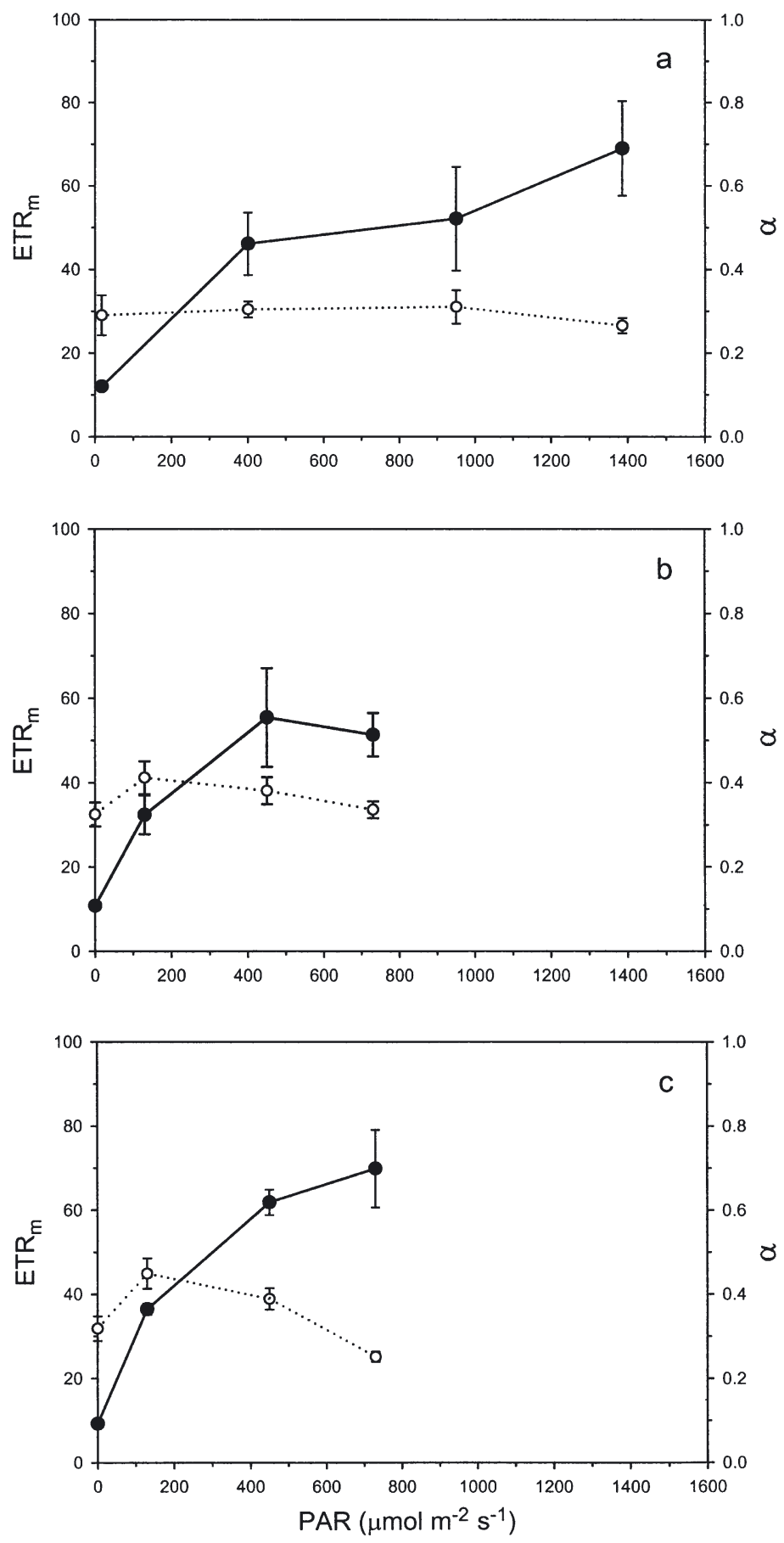

Fig. 4. Zostera noltii and Cymodocea nodosa. (a,b) Upper and lower $Z$. noltii sites, respectively; (c) C. nodosa site. Relationship between PAR and (•) maximum electron-transport rate $\left(\mathrm{ETR}_{\mathrm{m}}\right)$ and $(\mathrm{o})$ initial slope of rapid light curves $(\alpha)$

it to be good practice to measure $\mathrm{AF}$, since considerable differences are likely to be found and published values are rare.

Cymodocea nodosa presented typical shade-type plant responses, evidenced by the light-dependence of both photosynthetic efficiency and optimal quantum yield (Fig. 3c). These plants displayed a very efficient use of low light, and were very sensitive to higher irradiances. The relationship between the maximum electron-transport rate and irradiance (Fig. 4c) suggests that this species is strongly light-limited.

At the upper and lower edges of its vertical distribution, respectively, Zostera noltii clearly exhibited responses typical of sun- and shade-type plants during photosynthesis. Upper $Z$. noltii plants attained a significantly higher ETR $\mathrm{m}_{\mathrm{m}}$ (Fig. 2a,b), and the light-response curves saturated at higher irradiances than those of lower plants. This saturation resulted mainly from the consistently lower initial slopes of the curves, expressed by the $\alpha$ parameter, which in itself constitutes a useful indicator for distinguishing sun-adapted from shadeadapted plants (Henley 1993). The plot of $\mathrm{ETR}_{\mathrm{m}}$ vs ambient PAR at different times of day in Fig. 4 represents a diurnal global light-response curve. It allowed an overall analysis of the reaction of the $2 \mathrm{Z}$. noltii types to increasing irradiance, and showed that the $\checkmark$ lower plants were more efficient in the use of limiting irradiance, whereas the upper plants responded better at higher PAR values. Similar intraspecific differences have been described previously for subtidal seagrass species growing at different depths (Schwarz et al. 2000) or acclimated to different irradiances (Major \& Dunton 2002), but this is the first time that these differences have been described for an intertidal seagrass.

The fact that a particular Zostera noltii type growing in the upper intertidal displayed a sun-adapted response is not particularly interesting in itself. Interesting is the particular conditions to which $Z$. noltii adapted in Ria Formosa.

On a day in which low tide occurs at noon, plants are emersed for ca. $10 \mathrm{~h}$, from 09:00 to 19:00 h, being exposed to direct sun light for the whole day. However, $Z$. noltii in the Ria Formosa intertidal never undergo severe desiccation because of the high density of their packed leaves, which retain water. In such conditions, $Z$. noltii is able to maintain some degree of photosynthetic carbon uptake through rapid diffusion of $\mathrm{CO}_{2}$ from the air (Leuschner et al. 1998). Such carbon uptake depends on light-driven photosynthesis, which, in our study, occurred throughout the whole period nearair exposure. The photosynthetic yield of upper $Z$. noltii was significantly lower than that of low intertidal plants, indicating that despite adaptation to a high-light environment, the plants must dissipate some energy, channelling it through a non-photochemical quenching pathway, a process that appears to be common amongst seagrasses (Ralph et al. 1998). Our observations support the existence of such a process in $Z$. noltii that involves thermal dissipation of energy, and a consequent reduction in the fluorescence emission yield. 
When high tide occurs at noon, plants receive the highest light intensities during the early morning hours and remain submersed for most of the day. Under these conditions, photosynthetic responses were similar to those when low tide occurred at noon (data not shown), indicating that their sun- and shadeadaptation is not related to time of the low tide, but to the vertical position of the plants.

Photosynthesis is usually measured by traditional methods such as gas-exchange techniques, but care must be taken as to the time of day at which samples are processed, as their recent light-exposure history has a significant effect on photosynthetic responses. Repeated measures of photosynthetic oxygen production are difficult to achieve over a diurnal cycle, particularly in underwater conditions. On the other hand, the chlorophyll fluorescence method provides information about lightdriven reactions only, and therefore cannot be used as a stand-alone method for assessing absolute photosynthetic production, because processes such as photorespiration and changes in rates of dark respiration cannot be accounted for (Beer et al. 1998). Another important aspect is that the spectral composition of the fluorometer's halogen lamp differs from that of ambient light, and this can influence the ETR values through possible chromatic regulation, with consequent effects on charge separation at the PSII level (Kroon at al. 1993). On balance, weighting the constraints and the advantages, PAM fluorometry remains the choice method for field estimates of photosynthesis, especially in aquatic environments.

The vertical distribution of seagrasses on the intertidal is associated with a diversity of level-dependent environmental conditions that lead to pronounced differences in the plants' ecophysiology, even within the same species, as shown here for Zostera noltii. We propose that attempts to characterize the photosynthetic production of an intertidal meadow should consider both diurnal fluctuations in the plants' photosynthetic activity as well as their vertical distribution frequency. The need for considering diurnal changes in photosynthesis is evidenced by the fact that $\mathrm{ETR}_{\mathrm{m}}$ (which in theory is directly correlated with gross photosynthesis) varies throughout the day within a range that is 3 to 4 times greater than its lowest value, which occurs at the onset of photosynthesis. In an intertidal system like Ria Formosa, for example, a productivity estimate based solely on $\mathrm{ETR}_{\mathrm{m}}$ values obtained around noon would yield greatly overestimated results. Therefore, for productivity estimation purposes, daily integrals must be used to account for the dynamics of real-time adjustments in photosynthesis. A possible modelling approach would be to establish differentiated and vertically limited 'productivity bands' in intertidal meadows according to specific local conditions, and to calculate daily integrals of photosynthesis for each of those bands.
Acknowledgements. The authors wish to thank A. Alexandre, S. Cabaço, R. Machás, L. Mata and P. Neves for their precious help during field work. J.S. was supported by FCT grant PRAXIS XXI/BD/15782/98.

\section{LITERATURE CITED}

Abal EG, Dennison WC (1996) Seagrass depth range and water quality in southern Moreton Bay, Queensland, Australia. Mar Freshw Res 47:763-771

Abal EG, Lonegaran N, Bowen P, Perry CJ, Udy JW, Dennison WC (1994) Physiological and morphological responses of the seagrass Zostera capricorni Aschers to light intensity. J Exp Mar Biol Ecol 178:113-129

Bach SS, Borum J, Fortes MD, Duarte CM (1998) Species composition and plant performance of mixed seagrass beds along a siltation gradient at Cape Bolinao, The Philippines. Mar Ecol Prog Ser 174:247-256

Beer S, Björk M (2000) Measuring rates of photosynthesis of two tropical seagrasses by pulse amplitude modulated (PAM) fluorometry. Aquat Bot 66:69-76

Beer S, Vilenkin B, Weil A, Veste M, Susel L, Eschel A (1998) Measuring photosynthetic rates in seagrass by pulse amplitude modulated (PAM) fluorometry. Mar Ecol Prog Ser 174:293-300

Beer S, Larsson C, Poryan O, Axelsson L (2000) Photosynthetic rates of Ulva (Chlorophyta) measured by pulse amplitude modulated (PAM) fluorometry. Eur J Phycol 35: 69-74

Björk M, Uku J, Weil A, Beer S (1999) Photosynthetic tolerances to desiccation of tropical intertidal seagrasses. Mar Ecol Prog Ser 191:121-126

Demmig-Adams B (1998) Survey of thermal energy dissipation and pigment composition in sun and shade leaves. Plant Cell Physiol 39:474-482

Dennison WC, Alberte RS (1986) Photoadaptation and growth of Zostera marina L. (eelgrass) transplants along a depth gradient. J Exp Mar Biol Ecol 98:265-282

Dennison WC, Orth RJ, Moore KA, Stevenson JC, Carter V, Kollar S, Bergstrom PW, Batiuk RA (1993) Assessing water quality with submersed aquatic vegetation: habitat requirements as barometers of Chesapeak Bay health. BioScience 43:86-94

Duarte CM (1991) Seagrass depth limits. Aquat Bot 40:363-377

Durako MJ, Kunzelman JI (2002) Photosynthetic characteristics of Thalassia testudinum measured in situ by pulseamplitude modulated (PAM) fluorometry: methodological and scale-based considerations. Aquat Bot 73:173-185

Enríquez S, Merino M, Iglesias-Prieto R (2002) Variations in the photosynthetic performance along the leaves of the tropical seagrass Thalassia testudinum. Mar Biol 140: 891-900

Ensminger I, Xylander M, Hagen C, Braune W (2001) Strategies providing success in a variable habitat. III. Dynamic control of photosynthesis in Cladophora glomerata. Plant Cell Environ 24:769-779

Evans JR, Poorter H (2001) Photosynthetic acclimation of plants to growth irradiance: the relative importance of specific leaf area and nitrogen partitioning in maximizing carbon gain. Plant Cell Environ 24:755-767

Falkowski PG, LaRoche J (1991) Acclimation to spectral irradiance in algae. J Phycol 27:8-14

Figueroa FL, Jiménez C, Viñegla B, Pérez-Rodriguez E and 5 others (2002) Effects of solar UV radiation on photosynthesis of the marine angiosperm Posidonia oceanica from southern Spain. Mar Ecol Prog Ser 230:59-70 
Genty B, Briantais J, Baker N (1989) The relationship between the quantum yield of photosynthetic electrontransport and quenching of chlorophyll fluorescence. Biochim Biophys Acta 990:87-92

Henley WJ (1993) Measurement and interpretation of photosynthetic light-response curves in algae in the context of photoinhibition and diel changes. J Phycol 29:729-739

Jassby AD, Platt T (1976) Mathematical formulation of the relationship between photosynthesis and light for phytoplankton. Limnol Oceanogr 21:540-547

Kenworthy WJ, Fonseca MS (1996) Light requirements of seagrasses Halodule wrightii and Syringodium filiforme derived from the relationship between diffuse light attenuation and maximum depth distribution. Estuaries 19:740-750

Koch EW (2001) Beyond light: physical, geological and geochemical parameters as possible submersed aquatic vegetation habitat requirements. Estuaries 24:1-17

Krause GH, Weis E (1991) Chlorophyll fluorescence and photosynthesis: the basics. Annu Rev Plant Physiol Plant Mol Biol 42:313-349

Kroon B, Prézelin BB, Schofield O (1993) Chromatic regulation of quantum yields for photosystem II charge separation, oxygen evolution, and carbon fixation in Heterocapsa pygmaea (Pyrrophyta). J Phycol 29:453-462

Leuschner C, Landwehr S, Mehlig U (1998) Limitation of carbon assimilation of intertidal Zostera noltii and $Z$. marina by desiccation at low tide. Aquat Bot 62:171-176

Editorial responsibility: Otto Kinne (Editor),

Oldendorf/Luhe, Germany
Major KM, Dunton KH (2002) Variations in light-harvesting characteristics of the seagrass, Thalassia testudinum: evidence for photoacclimation. J Exp Mar Biol Ecol 275: 173-189

Ort D (2001) When there is too much light. Plant Physiol (Rockv) 125:29-32

Ralph PJ, Gademann R, Dennison WC (1998) In situ seagrass photosynthesis measured using a submersible, pulse-amplitude modulated fluorometer. Mar Biol 132: 367-373

Schreiber U, Horrmann H, Neubauer C, Klughammer C (1995) Assessment of photosystem II photochemical quantum yield by chlorophyll fluorescence quenching analysis. Aust J Plant Physiol 22:209-220

Schwarz AM, Björk M, Buluda T, Mtolera M, Beer S (2000) Photosynthetic utilisation of carbon and light by two tropical seagrass species as measured in situ. Mar Biol 137:755-761

Seaton G, Walker D (1990) Chlorophyll fluorescence as a measure of photosynthetic carbon assimilation. Proc R Soc Lond Ser B 242:29-35

Seddon S, Cheshire AC (2001) Photosynthetic response of Amphibolis antarctica and Posidonia australis to temperature and desiccation using chlorophyll fluorescence. Mar Ecol Prog Ser 220:119-130

Sokal RR, Rohlf FJ (1981) Biometry: the principles and practice of statistics in biological research, 2nd edn. WH Freeman, New York

Submitted: December 20, 2002; Accepted: May 6, 2003

Proofs received from author(s): July 22, 2003 